Open Access

\title{
Emerging clean transportation technologies and distribution of reduced greenhouse gas emissions in Southern California
}

\author{
ChangKeun Park', JiYoung Park ${ }^{2^{*}}$ and Simon Choi ${ }^{3,4}$
}

\author{
* Correspondence: \\ jp292@buffalo.edu \\ ${ }^{2}$ Department of Urban and \\ Regional Planning, University at \\ Buffalo, The State University of New \\ York, 228 Hayes Hall, Buffalo, NY \\ 14214-3087, USA \\ Full list of author information is \\ available at the end of the article
}

\begin{abstract}
Technological innovation in transportation and the related industrial and entrepreneurial ecosystems can reduce urban environmental risks, maintaining urban environments. This study measures inter-county spillovers of the greenhouse gas (GHG) emissions impact associated with economic activity changes in the Southern California region when emerging clean transportation technologies are introduced to the region. Using a pseudo 'top-down' method, we successfully distributed the state level GHG emissions data to the county level because the GHG emissions inventory is not supported below the state level by the U.S. Environmental Protection Agency. Using the Environmental Southern California's Inter-county Social Accounting Matrix (ESCI-SAM) model and a bridge connecting two digit NAICS sectors to the GHG emissions inventory sectors, the spillover effects were measured by replacing of existing final demand for seven counties in the Southern California region. Furthermore, this study developed an extended method to discover how the effect of seven counties of the region is distributed to the rest of California excluding the seven counties, the rest of the U.S., and the rest of the world, respectively. While this study tried to measure how alternative, new clean technology freight vehicles that meet the goal of the Scoping Plan of California could spill over the region, the model developed in this study can be used for the diverse scenario simulations that involve an introduction of green economy that regulates $\mathrm{GHG}$ emissions of a local region.
\end{abstract}

Keywords: Greenhouse gas emissions, Environmental economic model, Local spillover impacts, Spatial disaggregation

\section{Introduction}

Technological innovation in transportation and the related industrial and entrepreneurial ecosystems can reduce urban environmental risks, maintaining urban environments (Lo and Tang 2014). The greenhouse gas (GHG) emissions are generated mostly from the concentration of people, economic activities and the use of transportation systems in urban areas. To control global warming, global efforts are focusing on how to reduce their GHG emissions generated in urban areas (Park and Page, 2017).

The global $\mathrm{CO}_{2}$ emissions in 2008 reached more than 30 billion tons, representing 41\% increase against the 1990 emission level (Olivier et al., 2011). Global efforts to mitigate climate change have contributed to the coordinated global actions over the last decades. As a result, the Kyoto Protocol to the United Nations Framework

(c) The Author(s). 2017 Open Access This article is distributed under the terms of the Creative Commons Attribution 4.0 International License (http://creativecommons.org/licenses/by/4.0/), which permits unrestricted use, distribution, and reproduction in any medium provided you give appropriate credit to the original author(s) and the source, provide a link to the Creative Commons license, and indicate if changes were made. 
Convention on Climate Change (UNFCCC) was adopted in 1997 which legally bound Annex I Parties ${ }^{1}$ to reduce their Greenhouse Gas (GHG) emissions by at least $5 \%$ below the 1990 emission level during the commitment period 2008 to 2012. Especially, the U.S. had been required to reduce GHG emissions by 7\% (UNFCCC, 1997).

In the U.S., both national and domestic efforts were introduced. President Bush released several plans in 2002 to reduce GHG emissions per unit of economic activity by $18 \%$ up to 2012 . To meet this goal, dozens of federal programs (including partnerships, consumer information campaigns, incentives, and mandatory regulations) combined with state and local efforts are on track (U.S. DOS, 2007). Also, the California Global Warming Solutions Act of 2006 (AB 32) and the Senate Bill 375 under AB32 requested that the Air Resources Board prepare a Scoping Plan for California State in order to attain significant reduction of GHG emissions in the state. Along with the Act, California set the goal to reach the 1990 emission level of California by 2020 and $80 \%$ of the 1990 emission level by 2050 (CARB, 2008). Under these control of regulations, the Southern California region also outlined a plan that follows the regulation framework and contributes to reducing the GHG emissions.

Under the situation in California which is one of the most active states participating in the GHG reduction efforts in the U.S., quantifying the socioeconomic impact and regional competitive analysis is critical to the current and future economy of local regions in California. Efforts to reduce GHG emissions from the transportation sector are related to the highway vehicle controls because they account for 78 percent of total transportation emissions in 2007 (EIA, 2009). The efforts can be achieved via various policies mixed: implementing a carbon constraint, raising efficiency standards for automobiles, blending low-carbon fuels with gasoline, and changing land-use patterns through urban design and planning (Greene and Shafer, 2003). To reduce the transportation emissions, various emerging transportation technologies were introduced. Because drivetrain and vehicle categories generate the largest portion on fuel consumption, the fuel consumption from stop-and-start behavior hybrid vehicles offers 20 to 30\% reduction rates. Also, the fuel consumption reduction from aerodynamic technologies takes about $10 \%$. Further, technical improvements have been occurring in motor, transmission, aerodynamics, light-weighting, and so on. For example, new hard duty vehicles technically improved could offer 35\% reductions of GHG emissions (AEA, 2011; European Commission, 2014).

Because entrepreneurial activities for a region play an important role to grow the region's economy (Park and Page, 2017; Acs \& Armington, 2004; Audretsch, 2007), the GHG emissions may also increase due to economic development. While Cooke (2016) addressed that entrepreneurship ecosystems in a city and many supporting networks of coordinating entities lead to new and diverse business opportunities, if the reduction efforts are concentrated to the transportation sector, a region's environmental regulations for the GHG emissions may not negatively affect the economic performance of entrepreneurial ecosystems. This study tests how an alternative way of GHG policy could improve the spillover effects of GHG emissions via domestic trade in the U.S.

Furthermore, an advanced tool development that is used for measuring the socioeconomic impact of GHG emissions can be a challenging task for local regions, because the tool needs to utilize well-established national and/or international collaborative efforts on the GHG emissions. Especially, measuring the inter-county spillovers of the 
GHG emissions effect associated with economic activity changes in California needs to establish a multiregional economic model for the region.

In this study, we selected Southern California as a local region in California and developed a Southern California's Inter-County Social Accounting Matrix model (SCI-SAM). Also, we extended the SCI-SAM model toward building an environmental SCI-SAM model (ESCI-SAM) for estimating the GHG emissions of the region. While the methodological approach to constructing ESCI-SAM is straightforward to following previous studies suggested in McGregor et al. (2008) and Turner et al. (2007), the first important contribution in this study is to develop an approach that distributes upper regional level GHG emissions inventory to the lower local level. The GHG emissions inventory is usually existed at the national level and the state level in the U.S. In the case of California, the GHG emissions inventory at the state level is only available. Through the methodology adopted in this study, we extended the GHG emissions inventory from the state level to the county level.

To distribute the GHG emissions inventory at the state level to the county level of California, a pseudo 'top-down' approach was introduced, which allowed the GHG emissions inventory of California to be applied to ESCI-SAM for the estimation of the spillover effect at the county level. We applied the assumption of replacing the current demand for freight vehicles with new clean technology freight vehicles in order to analyze the spillover effect. Based on the results of spillover effect analysis, we also developed a model discovering how the emission effect of seven counties in Southern California would be distributed to the rest of California excluding the seven counties, the rest of the U.S., and the rest of the world, respectively. The development of distribution model is the second important contribution of this study.

Finally, most of studies described in Section 2, the literature review section, are associated with international trade impact using the input-output (IO) model, focusing not only on the estimation of the environmental impact of GHG emissions but also the allocation of the responsibility of $\mathrm{CO}_{2}$ emissions. However, it is rare to find a study that investigates the implication of GHG emissions from domestic trade. Another contribution of this study to the empirical research is to provide the significance of GHG emissions associated with domestic trade activities.

Combing our new ESCI-SAM model and the top-down allocation technique, this study could provide valuable information to local government policy makers and planners who are confronted with efforts to reducing the GHG emissions. Furthermore, the results of spillover effect analysis and the extended model applied in this study will be useful to various stakeholders because the distribution of GHG emissions can be simulated when reliable grounds are needed for the decision of their own standpoint.

In the next section, we reviewed previous studies related to GHG emissions. Data and models are presented in Section 3. Results and conclusions are followed in Sections 4 and 5, respectively.

\section{GHG emissions, trade, and input-output models}

Many researchers have adopted the input-output (IO) model approaches to assess the environmental impact of GHG emissions that are embodied in international trade. Using an IO model, especially a multiregional input-output model (MRIO), it 
was not only possible to estimate the direct and indirect environmental impact of GHG emissions, but also allocate total pollution and resource use embodiments of traded commodities (Wiedmann et al., 2007; Lin and Sun, 2010). The IO and MRIO model applications also contributed to understand of the responsibility of $\mathrm{CO}_{2}$ emissions.

International trade raised the responsibility for GHG emissions. In the Kyoto protocol, territorial principle which accounts for emissions from domestic sources only is referred as the reduction criterion when setting up the base year amount of GHG emissions and naturally ignored international trade (Lenzen et al., 2004; Kratena and Meyer, 2010). This viewpoint had evoked the core issue of how to allocate the responsibility for GHG emissions if a country heavily relies on international trade. Regarding this responsibility, Hoekstra and Janssen (2005) explored the 'use, 'make', and 'embodied' notions. Eder and Narodoslawsky (1999) explicitly categorized environmental responsibility as six types: territorial, unrestricted beneficial, regional beneficial, unrestricted production-oriented, regional production-oriented and total responsibilities.

An IO approach addressed the percentage of $\mathrm{CO}_{2}$ emissions in importing goods. According to Wyckoff and Roop (1994), the import of $\mathrm{CO}_{2}$ intensive non-energy products can distort a particular country's estimated $\mathrm{CO}_{2}$ emissions level as an artificially low level. For example, if a country imports products from other countries which did not participate in an international agreement such as the Kyoto protocol, the $\mathrm{CO}_{2}$ embodied in these imports would not be counted for $\mathrm{CO}_{2}$ emissions level of the importing country. This is often referred to as a carbon leakage. Adopting an MRIO model and assuming that the technology level of trading countries is identical, they revealed about $13 \%$ of the total $\mathrm{CO}_{2}$ emissions of the six largest OECD countries - Canada, France, Germany, Japan, the UK and the U.S. - were originated from the manufacturing imports. Similarly, Nijdam et al. (2005) quantified the environmental load of Dutch private consumption using a single region IO model for GHG emissions. They revealed that food production, room heating and auto-car are the most important elements, presenting that $49 \%$ of the environmental load of the consumption takes place abroad. Sánchez-Chóliz and Duarte (2005) also analyzed the sectoral impacts of Spanish international trade relationship on the present level of atmospheric pollution using the Spanish national IO model. They found that sectors such as transport material, mining and energy, non-metallic industries, chemical and metals are $\mathrm{CO}_{2}$ exporters; other services, construction, transport material and food sectors are the major $\mathrm{CO}_{2}$ importers.

The responsibility issue of $\mathrm{CO}_{2}$ emissions is viewed from an accounting principle aspect of producers and consumers. Open economy countries that make a significant net export of $\mathrm{CO}_{2}$ intensive products should devote additional efforts satisfying the domestic $\mathrm{CO}_{2}$ emission target (Munksgarrd and Pedersen, 2001); they applied Danish IO tables for the total $\mathrm{CO}_{2}$ emissions analysis based on production and consumption account models, assuming imported commodities are produced by identical technology to the Danish. The production account model was used for estimating direct $\mathrm{CO}_{2}$ emissions when producing export commodities and measuring indirect $\mathrm{CO}_{2}$ emissions from the production of inputs used in exports. Applying the consumption model, $\mathrm{CO}_{2}$ emissions generated from energy use, the production of domestic final demand goods and imports were estimated. The total gap of $\mathrm{CO}_{2}$ emissions from these principles is regarded as the net import of $\mathrm{CO}_{2}$ or $\mathrm{CO}_{2}$ trade balance. Furthermore, Peters (2008) emphasized the consumption - based approach when 
constructing the National Emissions Inventory (NEI) of SCI-SAM to be shifted from the standard production - based approach, more seriously considering to include imports instead of exports in NEI.

Indeed, it is imperative that most studies adopted a single regional (or a national) IO model with the assumption that the same technology was applied for imported goods; however, the assumption is likely to underestimate the significance of $\mathrm{CO}_{2}$ emissions embodied in internationally traded goods because each country has a different production technology level, as Ahmad and Wyckoff (2003) noticed. They analyzed 24 countries' $\mathrm{CO}_{2}$ emissions of domestic consumption and production, which are responsible for $80 \%$ of global $\mathrm{CO}_{2}$ emissions based on the investigation of technical coefficients from IO tables of each country. The estimated results suggest that $\mathrm{CO}_{2}$ emissions associated with domestic consumption goods were 5\% higher than the emissions related to domestic productions in OECD countries in 1995.

These errors may be significant for countries that have different technology levels and energy mixes. Peters and Hertwich (2006a) emphasized that regional technology differences should be endogenized in international trade patterns. They presented $67 \%$ of Norway's domestic $\mathrm{CO}_{2}$ emissions stemmed from the $\mathrm{CO}_{2}$ emissions embodied in imported goods. Moreover, the carbon leakage portion from the non-Annex I countries, defined as the $\mathrm{CO}_{2}$ emissions embodied in trade from non-Annex I countries divided by the total domestic $\mathrm{CO}_{2}$ emissions, was at least 30\% in 2000. Extending the previous study, Peters and Hertwich (2006b) applied a structural path analysis to the case of Norwegian households and estimated household environmental impacts of international trade in Norway. In this study, $61 \%$ of the $\mathrm{CO}_{2}, 87 \%$ of $\mathrm{SO}_{2}, 34 \%$ of $\mathrm{NO}_{\mathrm{x}}$ emissions from total Norwegian household consumption took place in foreign regions indirectly, whereas imported goods only accounted for $22 \%$ of total Norway household expenditure. Sizable portions of the emissions for food, business services, clothing, chemicals, furniture, cars, agriculture, textiles and most manufacturing sectors were generated in foreign regions.

In assessing the responsibility for GHG emissions, Lenzen et al. (2004) took a consumption principle and set up a five-region IO model, which consists of Denmark, Germany, Sweden, Norway and the rest of the world in order to calculate $\mathrm{CO}_{2}$ multipliers and trade balances. They investigated the effect of aggregation on the model and errors in a single region IO model by considering multidirectional trade. In the case of Denmark, $11 \mathrm{Mt}$. surplus of $\mathrm{CO}_{2}$ trade in the single region IO model turned into the trade balance when the multidirectional trade is accounted for. It also examined that models constructed on aggregated data are likely to carry substantial errors.

Extending the $\mathrm{IO}$ approach to endogenizing and accounting for direct $\mathrm{CO}_{2}$ emissions consumed by households, McGregor et al. (2008) adopted a social accounting matrix (SAM) for more comprehensive reflection of incomes and expenditures, calculating the $\mathrm{CO}_{2}$ emissions embodied in international trade flows between Scotland and the rest of the UK. Based on the method proposed by Turner et al. (2007), they empirically applied an MRIO model to analyze not only the nature and significance of interregional environmental spillover effects within the UK, but also the existence of the $\mathrm{CO}_{2}$ trade balance between Scotland and the rest of the UK. 


\section{Data and models}

\section{The Southern California's Inter-County Social Accounting Matrix (SCI-SAM)}

Constructing a Southern California's Inter-County Social Accounting Matrix (SCISAM) type model requires resolving several problems in data and methodology. Because the SCI-SAM model is constructed at the county level, trade flow data among counties by each industry sector must be prepared, as well as the SAM data of each county.

Main methodologies applied to construct SCI-SAM are Geographically Weighted Regression (GWR) and Multiregional SAM (MSAM) construction approaches. Since there is no comprehensive inventory of inter-industrial trade flows at the county level, we followed the GWR approach explained in the study of Park (2006) for inter-county trade flows estimation. Also, constructing MSAM advances the two step approach suggested by Park et al. (2009; 2017) and Park and Park (2016) that focused on the construction of the MRIO model at the state level.

Since SCI-SAM provides economic impact information on a local strategy implemented in the Southern California Association of Governments (SCAG) region with San Diego County, SCAG can serve for the local decision-making with the consideration of the economic impact that may also occur in the adjacent county or vice versa. Therefore, SCI-SAM provides diverse local strategy simulation options in terms of economic impact for Southern California. Figure 1 shows the progress of constructing the SCI-SAM model.

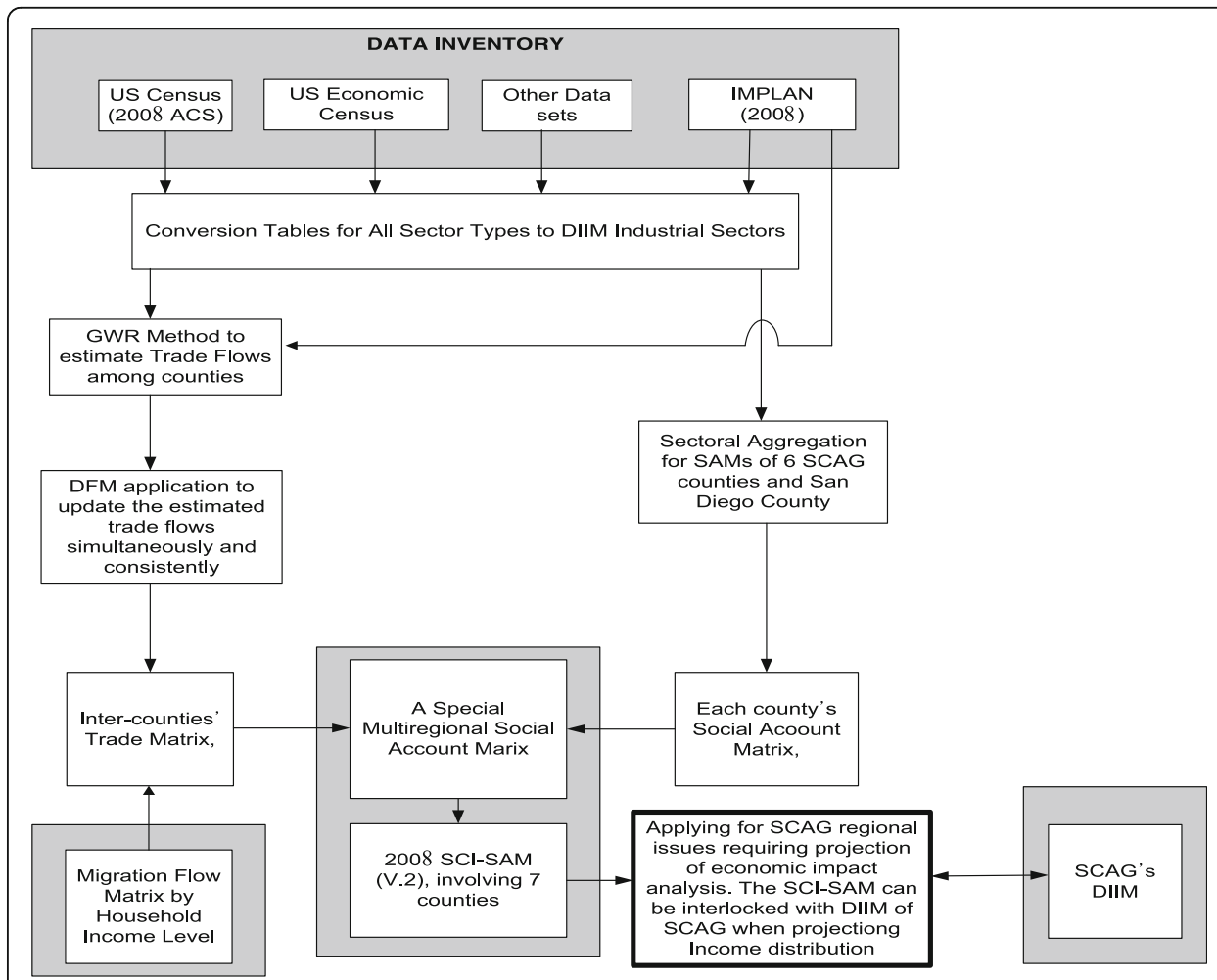

Fig. 1 Constructing 2008 SCI-SAM model: updating and spatial expansion 
The final inverse coefficient matrix structure of SCI-SAM would be expected to have the matrix form in Fig. 2. Because IMPLAN 2008 has a different sector system (440 sectors decreased from 509 sectors), we defined 20 industry sectors consistent to two digit NAICS sectors and another industry sector which cannot be identified in the current NAICS sector system but defined in the IMPLAN sector as well as 9 income sectors. Therefore, the inverse matrix has a $(30 \times 7) \times(30 \times 7)$ matrix form. Description of aggregated industry and income sectors of SCI-SAM are prepared in Table 1.

The inverse SCI-SAM matrix can be used for projecting income distribution based on the exogenous changes such as government investment or trade changes. Equation 1 shows the inverse SCI-SAM matrix defined as (I - MSAM $)^{-1}$. Because Y is defined as a column vector of regional specific government expenditures or trade, the changes in the final demand will impact other counties and industry sectors via Equation 1.

$$
\mathrm{X}=(\mathrm{I}-\mathrm{MSAM})^{-1} \mathrm{CY}
$$

where $\mathrm{X}=$ a total output matrix,

MSAM = the product of $\mathrm{C}$ and $\mathrm{A}$,

$\mathrm{C}=\operatorname{diag}\left(\mathrm{c}_{\mathrm{j} j}^{-1}\right)$ and $\mathrm{c}_{\mathrm{j} j}$ is trade flow for region $\mathrm{j}$, where $\mathrm{j}=1,2, \cdots, \mathrm{n}$,

$A=\operatorname{SAM}\left(\hat{X}^{I}\right)^{-1}, \hat{X}^{I}=\operatorname{diag}\left(x_{j j}^{I}\right)$, where $x_{j j}^{I}=$ the total input row vector for region $j$,

$\mathrm{Y}=\mathrm{a}$ column vector of regional specific government expenditures or trade changes, and

$(\mathrm{I}-\mathrm{MSAM})^{-1}=$ the inverse SCI-SAM matrix.

The Environmental Southern California's Inter-County Social Accounting Matrix (ESCI-SAM)

The Environmental Southern California's Inter-County Social Accounting Matrix (ESCI-SAM) is constructed based on the SCI-SAM model explained previously and

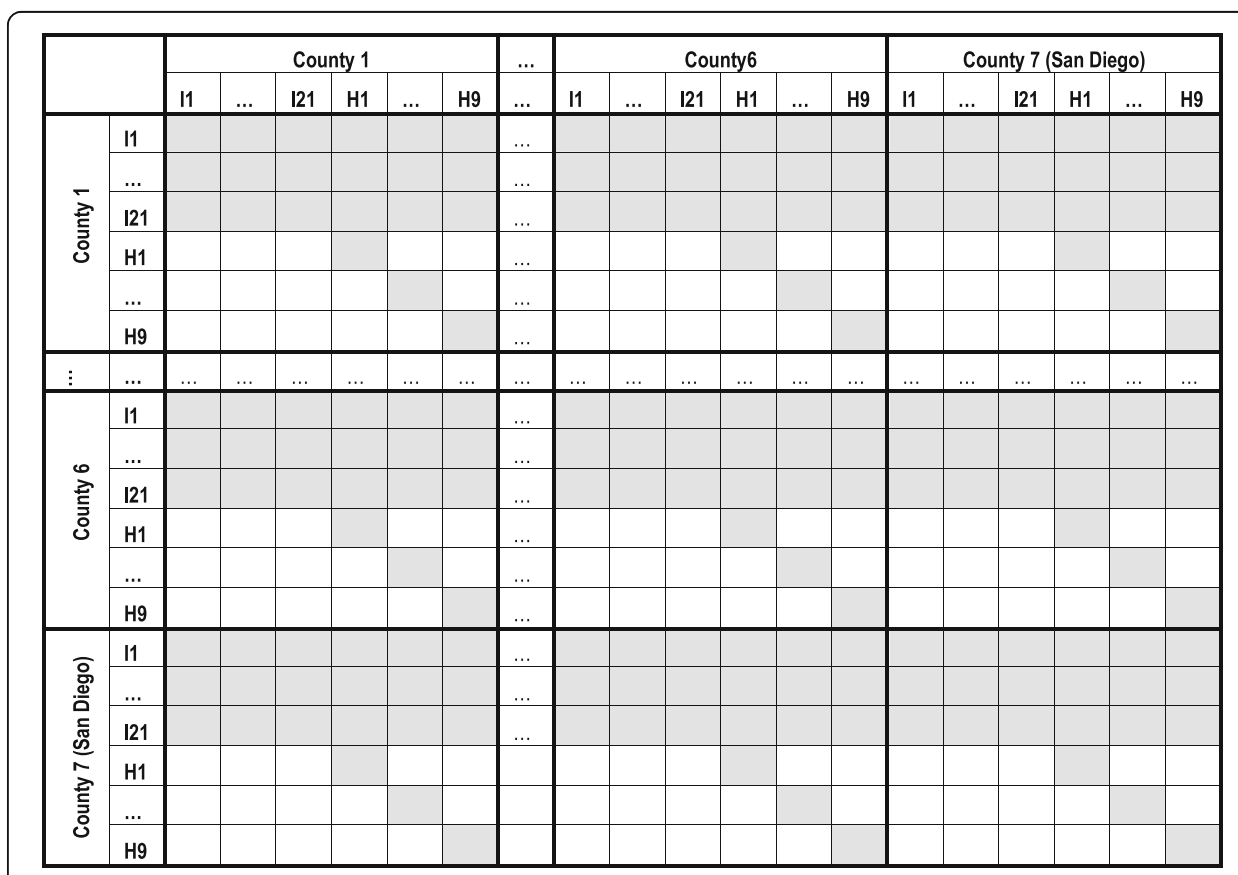

Fig. 2 The Inversed SCI-SAM Coefficients Matrix Structure.

Note: White cells identify zero values 
Table 1 The SCI-SAM's industry and income sector system

\begin{tabular}{|c|c|c|}
\hline SCI-SAM sectors & Two DIGIT Code System Used in Modeling & Sector Description \\
\hline SCI-IND 1 & 11 & Total Farm \\
\hline SCI-IND 2 & 21 & Natural Resources and Mining \\
\hline SCI-IND 3 & 22 & Utilities \\
\hline SCI-IND 4 & 23 & Construction \\
\hline SCI-IND 5 & 31 & Manufacturing \\
\hline SCI-IND 6 & 42 & Wholesale Trade \\
\hline SCI-IND 7 & 44 & Retail Trade \\
\hline SCI-IND 8 & 48 & Transportation and Warehousing \\
\hline SCI-IND 9 & 51 & Information \\
\hline SCI-IND 10 & 52 & Finance and Insurance \\
\hline SCI-IND 11 & 53 & Real Estate and Rental and Leasing \\
\hline SCI-IND 12 & 54 & Professional, Scientific and Technical Services \\
\hline SCI-IND 13 & 55 & Management of Companies and Enterprises \\
\hline SCI-IND 14 & 56 & Administrative and Support and Waste Services \\
\hline SCI-IND 15 & 61 & Educational Services \\
\hline SCI-IND 16 & 62 & Health Care and Social Assistance \\
\hline SCI-IND 17 & 71 & Arts, Entertainment, and Recreation \\
\hline SCI-IND 18 & 72 & Accommodation and Food Service \\
\hline SCI-IND 19 & 81 & Other Services \\
\hline SCI-IND 20 & 92 & Public Administration \\
\hline SCI-IND 21 & 93 & Not an industry \\
\hline SCI-INC 1 & 510 & Personal Income $=<\$ 9,999$ \\
\hline SCI-INC 2 & 511 & $\$ 10,000=<$ Personal Income $<\$ 15,000$ \\
\hline SCI-INC 3 & 512 & $\$ 15,000=<$ Personal Income $<\$ 25,000$ \\
\hline SCI-INC 4 & 513 & $\$ 25,000=<$ Personal Income $<\$ 35,000$ \\
\hline SCI-INC 5 & 514 & $\$ 35,000=<$ Personal Income $<\$ 50,000$ \\
\hline SCI-INC 6 & 515 & $\$ 50,000=<$ Personal Income $<\$ 75,000$ \\
\hline SCI-INC 7 & 516 & $\$ 75,000=<$ Personal Income $<\$ 100,000$ \\
\hline SCI-INC 8 & 517 & $\$ 100,000=<$ Personal Income $<\$ 150,000$ \\
\hline SCI-INC 9 & 518 & $\$ 150,000=<$ Personal Income \\
\hline
\end{tabular}

2008 GHG emission inventory of California from U.S. EPA. Matching the industry sectors of California's 2008 GHG emissions to the industry sectors of ESCI-SAM, we prepared Table 2. In case of sector discord, we matched both industry sectors applying the ratio of each industry output to the total industry output of that sector. For example, as shown in Table 2, the wholesale and retail sector of 2008 GHG emission inventory is divided into wholesale trade and retail trade for the ESCI-SAM industry sector based on the ratio of each sector's output to the total industry output of that sector. Not Specified industrial and Not Specified commercial sectors of 2008 GHG emission inventory were assigned to five industry sectors of ESCI-SAM (or ESCI-SAM sectors 10, 11, 12, 13 and 17) according to the ratio of each sector's output to the total industry output of that sector.

The ESCI-SAM is constructed on the basis of the traditional energy input-output analysis (Miller and Blair, 2009). First, $a j^{\text {th }}$ industry's GHG emission coefficient $d_{j}$ is defined: 
Table 2 Industry sectors matched between 2008 GHG emission inventory and the ESCI-SAM codes

\begin{tabular}{|c|c|c|}
\hline $\begin{array}{l}\text { GHG emission inventory economic } \\
\text { sector }\end{array}$ & ESCI-SAM Code & Description \\
\hline $\begin{array}{l}\text { Electricity Generation } \\
\text { (In State, Imports) }\end{array}$ & ESCI-IND 3 & Utilities \\
\hline Transportation & ESCI-IND 8 & Transportation and Warehousing \\
\hline CHP: Industrial & ESCI-IND 5 & Manufacturing \\
\hline Landfills & ESCI-IND 14 & $\begin{array}{l}\text { Administrative and Support and Waste } \\
\text { Services }\end{array}$ \\
\hline Manufacturing & ESCI-IND 5 & Manufacturing \\
\hline Mining & ESCI-IND 2 & Natural Resources and Mining \\
\hline Oil \& Gas Extraction & ESCI-IND 2 & Natural Resources and Mining \\
\hline Petroleum Marketing & ESCI-IND 5 & Manufacturing \\
\hline Petroleum Refining & ESCI-IND 5 & Manufacturing \\
\hline Pipelines & ESCI-IND 4 & Construction \\
\hline Wastewater Treatment & ESCI-IND 14 & $\begin{array}{l}\text { Administrative and Support and Waste } \\
\text { Services }\end{array}$ \\
\hline Not Specified Industrial & $\begin{array}{l}\text { ESCI-IND 10, } \\
11,12,13,17\end{array}$ & $\begin{array}{l}\text { Finance and Insurance } \\
\text { Real Estate and Rental and Leasing } \\
\text { Professional, Scientific and Technical Services } \\
\text { Management of Companies and Enterprises } \\
\text { Arts, Entertainment, and Recreation }\end{array}$ \\
\hline CHP: Commercial & ESCI-IND 14 & $\begin{array}{l}\text { Administrative and Support and Waste } \\
\text { Services }\end{array}$ \\
\hline Communication & ESCI-IND 9 & Information \\
\hline Domestic Utilities & ESCI-IND 3 & Utilities \\
\hline Education & ESCI-IND 15 & Educational Services \\
\hline Food Services & ESCI-IND 18 & Accommodation and Food Service \\
\hline Health Care & ESCI-IND 16 & Health Care and Social Assistance \\
\hline Hotels & ESCI-IND 18 & Accommodation and Food Service \\
\hline National Security & ESCI-IND 20 & Public Administration \\
\hline Offices & ESCI-IND 14 & $\begin{array}{l}\text { Administrative and Support and Waste } \\
\text { Services }\end{array}$ \\
\hline Retail \& Wholesale & ESCI-IND 6, 7 & Wholesale Trade, Retail Trade \\
\hline Transportation Services & ESCI-IND 8 & Transportation and Warehousing \\
\hline Not Specified Commercial & $\begin{array}{l}\text { ESCI-IND 10, } \\
11,12,13,17\end{array}$ & $\begin{array}{l}\text { Finance and Insurance } \\
\text { Real Estate and Rental and Leasing } \\
\text { Professional, Scientific and Technical Services } \\
\text { Management of Companies and Enterprises } \\
\text { Arts, Entertainment, and Recreation }\end{array}$ \\
\hline Household Use & ESCI-IND 19 & Other Services \\
\hline Agriculture \& Forestry & ESCI-IND 1 & Total Farm \\
\hline Not Specified & ESCI-IND 21 & Not an industry \\
\hline
\end{tabular}

CHP (Combined heat and power) is the simultaneous production of both electricity and useful heat for application by the producer or to be sold to other users with the aim of better utilization of the energy used. Public utilities may utilize part of the heat produced in power plants and sell it for public heating purposes. Industries as auto-producers may sell part of the excess electricity produced to other industries or to electric utilities

$$
\mathrm{d}_{\mathrm{j}}=\frac{\mathrm{e}_{\mathrm{j}}}{\mathrm{x}_{\mathrm{j}}}
$$

where $e_{j}=$ the amount of GHG emissions in $j^{\text {th }}$ industry (tons per year), $\mathrm{x}_{\mathrm{j}}=$ the total output of the $\mathrm{j}^{\text {th }}$ producing sector (in dollars). 
Therefore, $a j^{\text {th }}$ industry's GHG emission coefficient $d_{j}$ means the amount of GHG emissions which are needed to produce one dollar's worth of $\mathrm{j}^{\text {th }}$ industry output. As a matrix form, this can be presented:

$$
\mathrm{D}=\mathrm{EX} \hat{\mathrm{X}}^{-1}
$$

where $\mathrm{D}=\operatorname{diag}\left(\mathrm{d}_{\mathrm{jj}}\right), \mathrm{E}=\operatorname{diag}\left(\mathrm{e}_{\mathrm{jj}}\right)$, and $\hat{\mathrm{X}}^{-1}=\operatorname{diag}\left(\mathrm{x}_{\mathrm{jj}}{ }^{-1}\right)$, where $\mathrm{j}=1,2, \cdots, \mathrm{n}$.

Then, the total GHG emissions matrix $\mathrm{T}$ is developed by as:

$$
\mathrm{T}=\mathrm{DX}=\mathrm{D}(\mathrm{I}-\mathrm{MSAM})^{-1} \mathrm{CY}
$$

where D = a GHG emission coefficient matrix,

$\mathrm{C}=\mathrm{a}$ trade coefficient matrix, and

$\mathrm{D}(\mathrm{I}-\mathrm{MSAM})^{-1}=$ the ESCI-SAM model.

In Table 3, the 2008 GHG emission inventory and GHG emission coefficients by each sector of California are presented. The GHG emission coefficients are derived by dividing each sector's GHG emission amount by each sector's total industry output. Transportation and Warehousing, Utilities, and Manufacturing took the top three sectors of California's GHG emissions in 2008.

Table 3 GHG emissions and GHG emission coefficients of California

\begin{tabular}{llc}
\hline ESCl-SAM sectors & GHG emissions & GHG emission coefficients \\
\hline 1 Total Farm & $28.25(5.9)$ & 591.43 \\
2 Natural Resources and Mining & $17.23(3.6)$ & 819.69 \\
3 Utilities & $117.51(24.6)$ & 1837.12 \\
4 Construction & $2.62(0.5)$ & 14.67 \\
5 Manufacturing & $68.54(14.3)$ & 88.88 \\
6 Wholesale Trade & $0.39(0.1)$ & 2.5 \\
7 Retail Trade & $0.53(0.1)$ & 3.05 \\
8 Transportation and Warehousing & $175.57(36.8)$ & 2060.89 \\
9 Information & $0.17(0.0)$ & 0.62 \\
10 Finance and Insurance & $1.52(0.3)$ & 7.01 \\
11 Real Estate and Rental and Leasing & $2.91(0.6)$ & 6.96 \\
12 Professional, Scientific and Technical Services & $1.73(0.4)$ & 6.42 \\
13 Management of Companies and Enterprises & $0.32(0.1)$ & 6.78 \\
14 Administrative and Support and Waste Services & $10.55(2.2)$ & 224.21 \\
15 Educational Services & $0.98(0.2)$ & 39.66 \\
16 Health Care and Social Assistance & $1.5(0.3)$ & 8.75 \\
17 Arts, Entertainment, and Recreation & $0.47(0.1)$ & 9.21 \\
18 Accommodation and Food Service & $4.21(0.9)$ & 44.94 \\
19 Other Services & $28.45(6.0)$ & 329.22 \\
20 Public Administration & $0.26(0.1)$ & 1.49 \\
21 Not an industry & $14.02(2.9)$ & $477.74(100)$ \\
Total & & \\
1. Unt & & \\
\hline
\end{tabular}

1. Unit of GHG emissions: million tons

2. Unit of GHG emission coefficients: ton per one million dollar output 


\section{Spillover effect distribution model}

After a spillover effect analysis using the ESCI-SAM model, it may be important to distribute the leakage of the spillover effect to other regions, which was not specified in the ESCI-SAM model. The basic concept of the approach to estimate total effects distributed to the rest of California excluding the seven counties (defined as RCA), the rest of the U.S. (defined as RUS), and the rest of the world (defined as ROW) is demonstrated in Fig. 3. The detailed description of the procedure follows in the next paragraphs.

Each county's contribution to the total effects needs to be estimated. The definition of total industry outputs is $\mathrm{TIO}_{\mathrm{ij}}$, where $\mathrm{i}$ represents industry sector and $\mathrm{j}$ stands for each county in the ESCI-SAM model. To calculate each county's contribution for each industry, we aggregated total industry output of each county by industry which can be estimated via the ESCI-SAM model (defined as $\sum_{\mathrm{j}} \mathrm{TIO}_{\mathrm{ij}}$ ). After that, we calculated the proportion of each county's contribution to each industry:

$$
\left(\mathrm{PTIO}_{\mathrm{j}}\right)_{\mathrm{i}}=\mathrm{TIO}_{\mathrm{ij}} / \sum_{\mathrm{j}} \mathrm{TIO}_{\mathrm{ij}} \text {, where } \sum_{\mathrm{j}} \mathrm{PTIO}_{\mathrm{j}}=1
$$

Because IMPLAN provides the domestic imports vector for the out-of-seven-county region (that is, RCA + RUS), we could estimate the proportional contribution of each county and of each industry to RUS (defined as PRCAUS $\mathrm{P}_{\mathrm{ij}}$ ) using the information given: the definition of RCAUS $_{i}$ is $(R C A+R U S)_{i}$ and the proportion of RCAUS Rij $_{\text {with respect }}$ to the total industry output (that is, $\sum_{\mathrm{i}} \mathrm{RCAUS}_{\mathrm{i}}$ ) is suggested in equation 6 :

$$
\text { PRCAUS }_{\mathrm{ij}}=\left(\mathrm{PTIO}_{\mathrm{j}}\right)_{\mathrm{i}} \mathrm{x}\left(\mathrm{RCAUS}_{\mathrm{i}} / \sum_{\mathrm{i}} \text { RCAUS }_{\mathrm{i}}\right)
$$

Similarly, the proportional contribution of each county and of each industry to ROW, PROW $_{\mathrm{ij}}$, is calculated as:

$$
\text { PROW }_{i j}=\left(\text { PTIO }_{j}\right)_{i} x\left(R_{i} / \sum_{i} R_{i} W_{i}\right)
$$

where ROW $\mathrm{W}_{\mathrm{i}}$ equals the foreign imports for the seven-county region.

Multiplying the total effects estimated by the ESCI-SAM model to PRCAUS Pij $_{\text {and }}$ PROW $_{\mathrm{ij}}$, we could calculate the distributed spillover effects to the out-of-seven-county region and ROW, respectively. However, the effects distributed to the out-of-sevencounty region are divisible into two parts; the effects distributed to RCA and RUS.
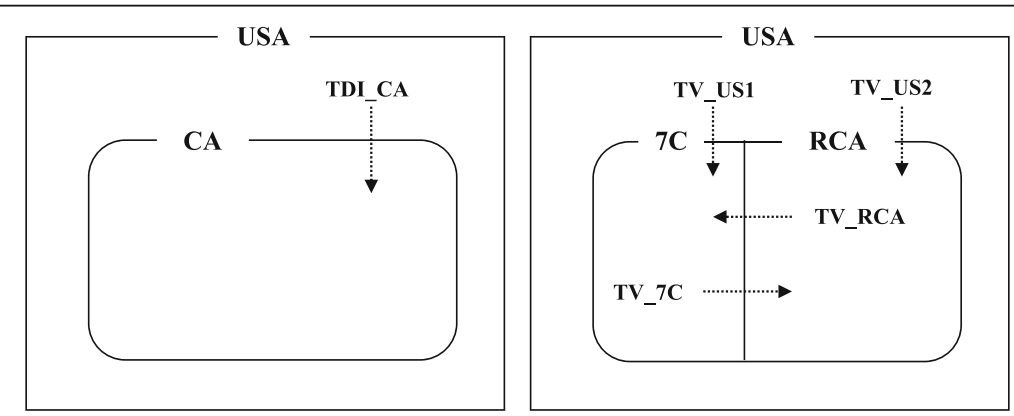

Fig. 3 Decomposing Total Domestic Imports of California Using Secondary Data.

Note: 1. TDI_CA = Total domestic imports of California. 2. TV_US1 = Total values in-traded from the U.S. excluding the rest of California regions. 3. TV_US2 = Total values in-traded from the U.S. excluding the

7-county region. 4. TV_RCA = Total values in-traded from other California regions. 5. TV_7C $=$ Total values in-traded from 7-county region 
A new approach needs to be developed to split the effects into RCA and RUS. First of all, the total trade values staying in California are estimated using the total domestic imports of California, seven counties, and California excluding the seven counties. For the next step, the proportion of the total trade values staying in California (the total trade values in California are divided by the total industry output values) is applied to estimate the spillover effects distributed to RCA only.

Since the total trade values staying in California (TV_RCA and TV_7C in Fig. 3) cannot be estimated using the secondary data source of the IMPLAN data, we redefined the total domestic imports of California, seven counties, and California excluding the seven counties based on a trade flow concept as demonstrated in Fig. 3. Because TDI_CA in Fig. 3 means the trade values which come into California from all other U.S. regions, the total domestic imports of California (TDI_CA) should be same as TV_US1 and TV_US2. The total domestic imports of seven counties (defined as TDI_7C) represent the combination of TV_US1 and TV_RCA. Similarly, the total domestic imports of California excluding the seven counties (defined as TDI_RCA) is the combination of TV_US2 and TV_7C, expressed in equation 8:

$$
\begin{aligned}
& \text { TDI_CA }=\text { TV_US1 }+ \text { TV_US2, TDI_7C }=\text { TV_US1 }+ \text { TV_RCA, } \\
& \text { TDI_RCA }=\text { TV_US2 }+ \text { TV_-7C }
\end{aligned}
$$

Thus, the total trade values staying in California can be expressed by the total domestic imports of three regions in equation 9:

$$
\begin{aligned}
& \text { TDI_7C }+ \text { TDI_RCA }=\text { TV_US1 }+ \text { TV_RCA }+ \text { TV_US2 }+ \text { TV_7C } \\
& =\text { TDI_CA }+ \text { TV_RCA }+ \text { TV_7C } \\
& \therefore \text { TV_RCA }+ \text { TV_7C }=\text { TDI_7C }+ \text { TDI_RCA }- \text { TDI_CA }
\end{aligned}
$$

We adopted the total trade values staying in California to calculate the proportional contribution of each county and of each industry to RCA shown as:

$$
\mathrm{PRCA}_{\mathrm{ij}}=\left(\mathrm{PTIO}_{\mathrm{j}}\right)_{\mathrm{i}} \times\left(\mathrm{RCA}_{\mathrm{i}} / \sum_{\mathrm{i}} \mathrm{RCA}_{\mathrm{i}}\right)
$$

where, $\mathrm{RCA}_{\mathrm{i}}=$ total trade values staying in California for the seven-county region

Therefore, the proportional contribution of each county and of each industry to RUS $^{2}$ is simply calculated using equations 6 and 10 as shown:

$$
\text { PRUS }_{\mathrm{ij}}=\text { PRCAUS }_{\mathrm{ij}}-\mathrm{PRCA}_{\mathrm{ij}}
$$

Finally, the total effect (TE) of leakages to RCA, RUS and ROW are calibrated:

- Total effects of the rest of California: TE_RCA $\mathrm{A}_{\mathrm{ij}}=\mathrm{TE}_{\mathrm{ij}} \times \mathrm{PRCA}_{\mathrm{ij}}$

- Total effects of the rest of the U.S.: TE_RUS $S_{i j}=T_{i j} \times \operatorname{PRUS}_{i j}$

- Total effects of the rest of the World: TE_ROW ${ }_{i j}=T_{i j} x P_{i j} O W_{i j}$

- Total effect which remain within the seven counties: $\mathrm{TE}_{-} 7 \mathrm{C}_{\mathrm{ij}}=\mathrm{TE}_{\mathrm{ij}}-\left(\mathrm{TE}_{-} \mathrm{RCA}_{\mathrm{ij}}+\right.$ $\left.T E \_R U S_{i j}+T E \_R O W_{i j}\right)$.

\section{Results}

Applying the ESCI-SAM model with 2008 GHG emission inventory of California, the estimation results of the GHG emissions for Southern California are presented in 
Table 4 by the ESCI-SAM industry sector. In the last row, the total GHG emissions by each county were presented, where the value in parentheses is a percentage to the total GHG emissions of seven counties. The total GHG emissions of seven counties including Imperial, Los Angeles, Orange, Riverside, San Bernardino, Ventura and San Diego are estimated as 342.1 million tons. These amounts would account for $72 \%$ of the 2008 total GHG emissions (477.74 million tons) in California. Since GHG emissions from economic activities are related to fossil fuel usage, the main sources of GHG emissions for the relevant region's economy are associated with activities generating transportation and electricity. As seen in Table 3, Utilities and Transportation and Warehousing sectors made up $61.4 \%$ of the total GHG emissions of California, and this ratio goes up to $75.7 \%$ when the Manufacturing sector is included. Therefore, the proportion of GHG emissions of the Southern California region is greater than that of the total industry output of the region, which accounts for $54.4 \%$.

To compare GHG emissions of each county, Los Angeles comes to 25.3\% (86.6 million tons) of the total GHG emissions for seven counties. San Diego and Orange are followed as $16.1 \%$ (55.3 million tons) and 14.2\% (48.7 million tons), respectively. Except Imperial County, Transportation and Warehousing is the highest GHG emitted sector in each county taking from $35.2 \%$ through $50.9 \%$ of each county's total GHG emissions. The Utilities sector is the second highest GHG emissions sector between $18.7 \%$ and $27.5 \%$. Manufacturing is the third sector at $8.7 \%$ through $11.8 \%$ (Refer to Table 4 and Fig. 4).

Table 4 The estimated GHG emissions of the Southern California region, 2008

\begin{tabular}{|c|c|c|c|c|c|c|c|}
\hline Sector number & Imperial & Los Angeles & Orange & Riverside & San Bernardino & Ventura & San Diego \\
\hline 1 & $4.24(11.6)$ & $0.67(0.8)$ & $0.80(1.6)$ & $1.50(4.1)$ & $0.75(2.0)$ & $1.65(4.0)$ & $1.24(2.2)$ \\
\hline 2 & $0.48(1.3)$ & $1.03(1.2)$ & $0.69(1.4)$ & $0.53(1.5)$ & $0.85(2.3)$ & $1.24(3.0)$ & $0.57(1.0)$ \\
\hline 3 & $12.71(34.7)$ & 16.17(18.7) & $13.37(27.5)$ & 8.03(21.9) & $9.33(25.3)$ & $9.33(22.5)$ & $14.48(26.2)$ \\
\hline 4 & $0.12(0.3)$ & $0.50(0.6)$ & $0.38(0.8)$ & $0.31(0.8)$ & $0.24(0.6)$ & $0.26(0.6)$ & $0.49(0.9)$ \\
\hline 5 & $3.07(8.4)$ & 7.56(8.7) & $5.29(10.9)$ & $3.85(10.5)$ & $3.67(9.9)$ & $4.91(11.8)$ & $5.00(9.0)$ \\
\hline 6 & $0.01(0.0)$ & $0.07(0.1)$ & $0.05(0.1)$ & $0.02(0.1)$ & $0.02(0.0)$ & $0.03(0.1)$ & $0.05(0.1)$ \\
\hline 7 & $0.04(0.1)$ & $0.15(0.2)$ & $0.07(0.2)$ & $0.05(0.1)$ & $0.04(0.1)$ & $0.05(0.1)$ & $0.10(0.2)$ \\
\hline 8 & 12.07(33.0) & $44.06(50.9)$ & 19.94(41.0) & $17.11(46.8)$ & $17.75(48.1)$ & 16.48(39.7) & 19.43(35.2) \\
\hline 9 & $0.003(0.0)$ & $0.03(0.0)$ & $0.01(0.0)$ & $0.005(0.0)$ & $0.005(0.0)$ & $0.01(0.0)$ & $0.02(0.0)$ \\
\hline 10 & $0.06(0.2)$ & $0.35(0.4)$ & $0.22(0.5)$ & $0.09(0.3)$ & $0.08(0.2)$ & $0.20(0.5)$ & $0.27(0.5)$ \\
\hline 11 & $0.08(0.2)$ & $0.44(0.5)$ & $0.25(0.5)$ & $0.11(0.3)$ & $0.07(0.2)$ & $0.15(0.4)$ & $0.45(0.8)$ \\
\hline 12 & $0.04(0.1)$ & $0.40(0.5)$ & $0.21(0.4)$ & $0.10(0.3)$ & $0.08(0.2)$ & $0.16(0.4)$ & $0.36(0.7)$ \\
\hline 13 & $0.01(0.0)$ & $0.03(0.0)$ & $0.02(0.0)$ & $0.01(0.0)$ & $0.01(0.0)$ & $0.01(0.0)$ & $0.03(0.0)$ \\
\hline 14 & $1.17(3.2)$ & $3.57(4.1)$ & $2.36(4.9)$ & $1.42(3.9)$ & $1.20(3.2)$ & $2.39(5.8)$ & $3.91(7.1)$ \\
\hline 15 & $0.31(0.9)$ & $1.06(1.2)$ & $0.49(1.0)$ & $0.36(1.0)$ & $0.42(1.1)$ & $0.45(1.1)$ & $0.64(1.2)$ \\
\hline 16 & $0.13(0.4)$ & $0.63(0.7)$ & $0.28(0.6)$ & $0.18(0.5)$ & $0.19(0.5)$ & $0.21(0.5)$ & $0.37(0.7)$ \\
\hline 17 & $0.01(0.0)$ & $0.14(0.2)$ & $0.05(0.1)$ & $0.05(0.1)$ & $0.02(0.1)$ & $0.03(0.1)$ & $0.07(0.1)$ \\
\hline 18 & $0.23(0.6)$ & $0.89(1.0)$ & $0.43(0.9)$ & $0.31(0.8)$ & $0.27(0.7)$ & $0.31(0.8)$ & $0.68(1.2)$ \\
\hline 19 & $1.39(3.8)$ & $6.94(8.0)$ & $3.17(6.5)$ & $2.11(5.8)$ & $1.65(4.5)$ & $2.87(6.9)$ & $4.84(8.8)$ \\
\hline 20 & $0.03(0.1)$ & $0.08(0.1)$ & $0.02(0.1)$ & $0.03(0.1)$ & $0.02(0.1)$ & $0.03(0.1)$ & $0.06(0.1)$ \\
\hline 21 & $0.40(1.1)$ & $1.82(2.1)$ & $0.60(1.2)$ & $0.41(1.1)$ & $0.27(0.7)$ & $0.69(1.7)$ & $2.22(4.0)$ \\
\hline Total & $36.61(10.7)$ & $86.59(25.3)$ & $48.69(14.2)$ & $36.58(10.7)$ & $36.93(10.8)$ & $41.45(12.1)$ & $55.25(16.1)$ \\
\hline
\end{tabular}

1. Unit: million tons

2. The value in parentheses indicates a percentage to the total 


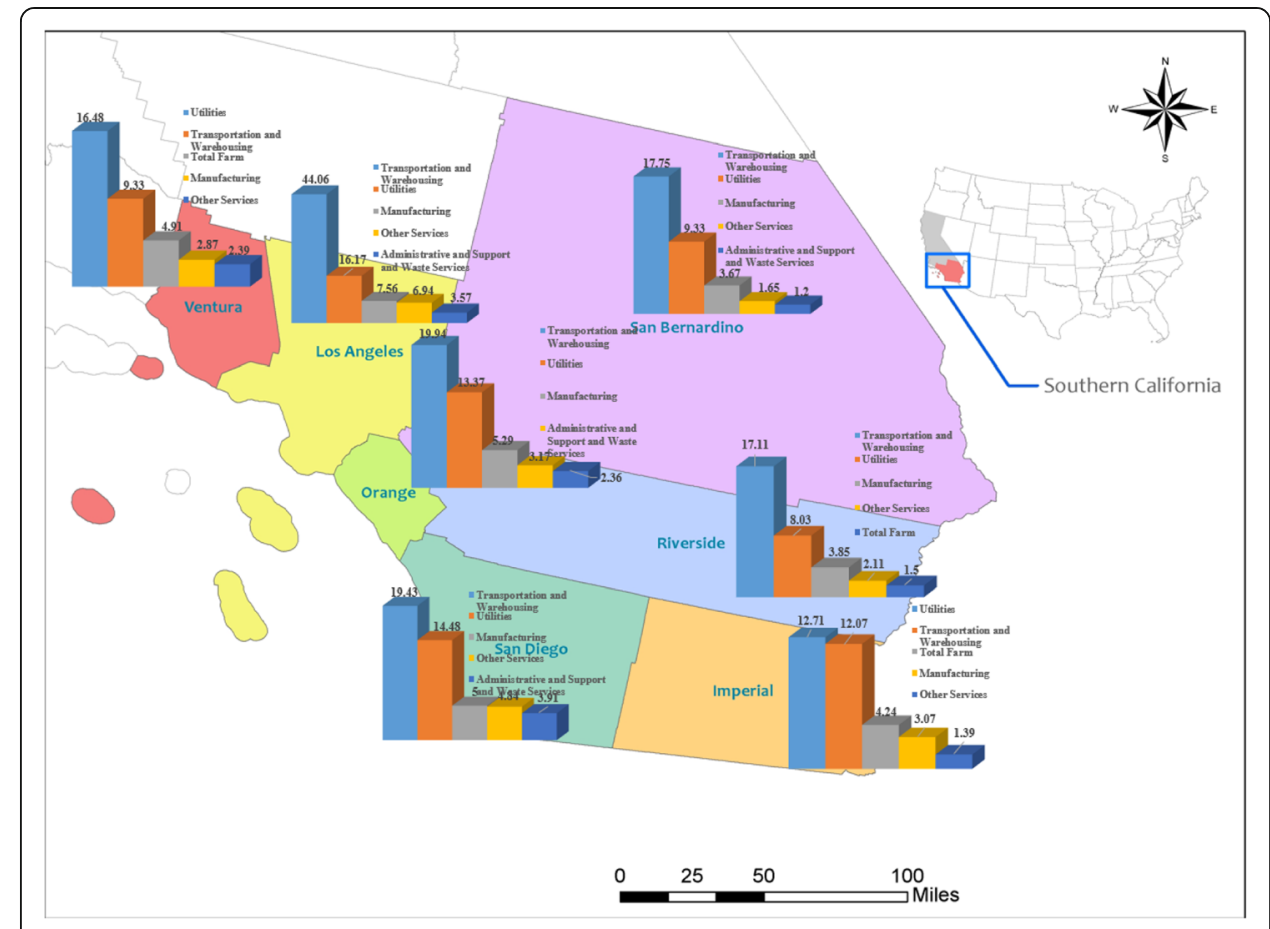

Fig. 4 Geographical estimation of GHG emissions for major industrial sectors in Southern California

In the case of Imperial County, Utilities is the first GHG emissions sector at $34.8 \%$ (12.7 million tons) and Transportation and Warehousing is the second GHG emissions sector (32.9\%, 12.1 million tons). The total Farm sector is the third GHG emissions sector at $11.6 \%$ of total GHG emissions of Imperial, although this sector was not included in the top three sectors of GHG emissions in the other counties.

Measuring the spillover effects of GHG emissions, we assumed that SCAG decided to replace the existing high $\mathrm{CO}_{2}$ emitted freight vehicles using diesel fuel (all of trucks, trains and ships) with new clean technology freight vehicles for satisfying the goal of the Scoping Plan. According to the decision, the final demand of the Transportation and Warehousing sector in Los Angeles County was reduced 100 million dollars. Based on the assumption, we conducted a spillover effect analysis to measure the change of GHG emissions in seven counties due to the change in the final demand. The total effects of this change in the final demand are presented as the change of GHG emissions in Table 5. The total reductions of GHG emissions in seven counties are estimated at 238,345 tons, and 53.4\% of these reductions would occur in Los Angeles. Through this table we could understand that most reductions of GHG emissions would take place in the Transportation and Warehousing sector in each county. The reduction rate of each county is within the range from $82.4 \%$ through $97.3 \%$ (See Fig. 5).

After the effect analysis, we developed a model that extends to figure out how these effects of seven counties are distributed to RCA, RUS and ROW, respectively. The effects distributed to these areas stand for the leakage driven from seven counties. In Table 6 and Fig. 6, we presented the effect results distributed with the reductions of GHG emissions.

Among the total reduction of GHG emissions in seven counties due to the change of final demand (238,345 tons), $0.8 \%$ of total reduction of GHG emissions (1,813.4 tons) 
Table 5 Total effects of final demand change in Southern California

\begin{tabular}{|c|c|c|c|c|c|c|c|}
\hline Sector number & Imperial & Los Angeles & Orange & Riverside & San Bernardino & Ventura & San Diego \\
\hline 1 & $-0.17(2.2)$ & $-0.04(0.0)$ & $-0.02(0.1)$ & $-0.06(0.6)$ & $-0.02(0.2)$ & $-0.16(0.4)$ & $-0.02(0.3)$ \\
\hline 2 & $-0.05(0.6)$ & $-0.12(0.1)$ & $-0.08(0.2)$ & $-0.05(0.6)$ & $-0.11(1.1)$ & $-0.17(0.4)$ & $-0.05(0.6)$ \\
\hline 3 & $-0.49(6.3)$ & $-1.08(0.8)$ & $-0.76(2.2)$ & $-0.42(4.4)$ & $-0.99(9.4)$ & $-0.88(2.1)$ & $-0.32(4.0)$ \\
\hline 4 & $-0.00(0.0)$ & $-0.03(0.0)$ & $-0.02(0.1)$ & $-0.02(0.2)$ & $-0.02(0.2)$ & $-0.03(0.1)$ & $-0.01(0.1)$ \\
\hline 5 & $-0.10(1.3)$ & $-0.66(0.5)$ & $-0.39(1.2)$ & $-0.20(2.1)$ & $-0.27(2.6)$ & $-0.45(1.1)$ & $-0.17(2.1)$ \\
\hline 6 & $-0.00(0.0)$ & $-0.01(0.0)$ & $-0.00(0.0)$ & $-0.00(0.0)$ & $-0.00(0.0)$ & $-0.00(0.0)$ & $-0.00(0.0)$ \\
\hline 7 & $-0.00(0.0)$ & $-0.01(0.0)$ & $-0.00(0.0)$ & $-0.00(0.0)$ & $-0.00(0.0)$ & $-0.00(0.0)$ & $-0.00(0.0)$ \\
\hline 8 & $-6.75(87.3)$ & $-123.96(97.3)$ & $-31.96(94.4)$ & $-8.48(88.5)$ & $-8.64(82.4)$ & $-38.67(93.7)$ & $-7.18(89.0)$ \\
\hline 9 & $-0.00(0.0)$ & $-0.00(0.0)$ & $-0.00(0.0)$ & $-0.00(0.0)$ & $-0.00(0.0)$ & $-0.00(0.0)$ & $-0.00(0.0)$ \\
\hline 10 & $-0.00(0.0)$ & $-0.03(0.0)$ & $-0.02(0.0)$ & $-0.01(0.1)$ & $-0.01(0.1)$ & $-0.03(0.1)$ & $-0.01(0.1)$ \\
\hline 11 & $-0.00(0.0)$ & $-0.02(0.0)$ & $-0.01(0.0)$ & $-0.00(0.0)$ & $-0.00(0.0)$ & $-0.01(0.0)$ & $-0.01(0.1)$ \\
\hline 12 & $-0.00(0.0)$ & $-0.05(0.0)$ & $-0.02(0.1)$ & $-0.01(0.1)$ & $-0.01(0.1)$ & $-0.02(0.1)$ & $-0.01(0.1)$ \\
\hline 13 & $-0.00(0.0)$ & $-0.00(0.0)$ & $-0.00(0.0)$ & $-0.00(0.0)$ & $-0.00(0.0)$ & $-0.00(0.0)$ & $-0.00(0.0)$ \\
\hline 14 & $-0.09(1.2)$ & $-0.53(0.4)$ & $-0.26(0.8)$ & $-0.13(1.4)$ & $-0.15(1.4)$ & $-0.38(0.9)$ & $-0.15(1.8)$ \\
\hline 15 & $-0.01(0.2)$ & $-0.12(0.1)$ & $-0.05(0.2)$ & $-0.03(0.3)$ & $-0.06(0.6)$ & $-0.06(0.1)$ & $-0.02(0.2)$ \\
\hline 16 & $-0.00(0.0)$ & $-0.04(0.0)$ & $-0.02(0.0)$ & $-0.01(0.1)$ & $-0.02(0.2)$ & $-0.02(0.0)$ & $-0.01(0.1)$ \\
\hline 17 & $-0.00(0.0)$ & $-0.01(0.0)$ & $-0.00(0.0)$ & $-0.00(0.0)$ & $-0.00(0.0)$ & $-0.00(0.0)$ & $-0.00(0.0)$ \\
\hline 18 & $-0.01(0.1)$ & $-0.06(0.0)$ & $-0.02(0.1)$ & $-0.01(0.1)$ & $-0.02(0.2)$ & $-0.02(0.1)$ & $-0.01(0.2)$ \\
\hline 19 & $-0.04(0.6)$ & $-0.50(0.4)$ & $-0.19(0.6)$ & $-0.13(1.4)$ & $-0.15(1.4)$ & $-0.33(0.8)$ & $-0.09(1.1)$ \\
\hline 20 & $-0.00(0.0)$ & $-0.00(0.0)$ & $-0.00(0.0)$ & $-0.00(0.0)$ & $-0.00(0.0)$ & $-0.00(0.0)$ & $-0.00(0.0)$ \\
\hline 21 & $-0.01(0.1)$ & $-0.08(0.1)$ & $-0.02(0.0)$ & $-0.01(0.1)$ & $-0.01(0.1)$ & $-0.04(0.1)$ & $-0.02(0.2)$ \\
\hline Total & $-7.74(3.2)$ & $-127.34(53.4)$ & $-33.85(14.2)$ & $-9.58(4.0)$ & $-10.49(4.4)$ & $-41.28(17.3)$ & $-8.06(3.4)$ \\
\hline
\end{tabular}

1. Unit: thousand tons

2. The value in parentheses is a percentage to the total

3. A negative sign indicates the reduction of GHG emissions

passed on RCA. The reduction of GHG emissions conveyed to RUS was projected with $1,049.4$ tons ( $0.4 \%$ of the total reduction) as the final demand of Los Angeles decreased. The reduction of GHG emissions distributed to ROW would reach 1,617.7 tons, taking $0.7 \%$ of the total reduction. Therefore, the reduction of GHG emissions that remains within the seven counties is estimated as 233,871 tons (98.1\%).

\section{Conclusions}

Concerns on the effect of global climate change have been increasing from many countries over the last decades. As the results of global actions that may mitigate climate change, the Kyoto Protocol to UNFCCC was adopted in 1997. Although the U.S. did not sign the Kyoto Protocol, dozens of federal programs to reduce GHG emissions were prepared from 2002. According to AB 32 and SB 375, ARB prepared a Scoping Plan for the state of California in order to participate in a global movement reducing GHG emissions.

Furthermore, while the negative relationship among urban economic performance and urban environments may exist, the complicated green city development should be examined by considering the entire urban utilities (Park and Page, 2017). In that sense, this study tried to measure how alternative, new clean technology applied to freight vehicles that meet the goal of the Scoping Plan of California could spill over the region. 


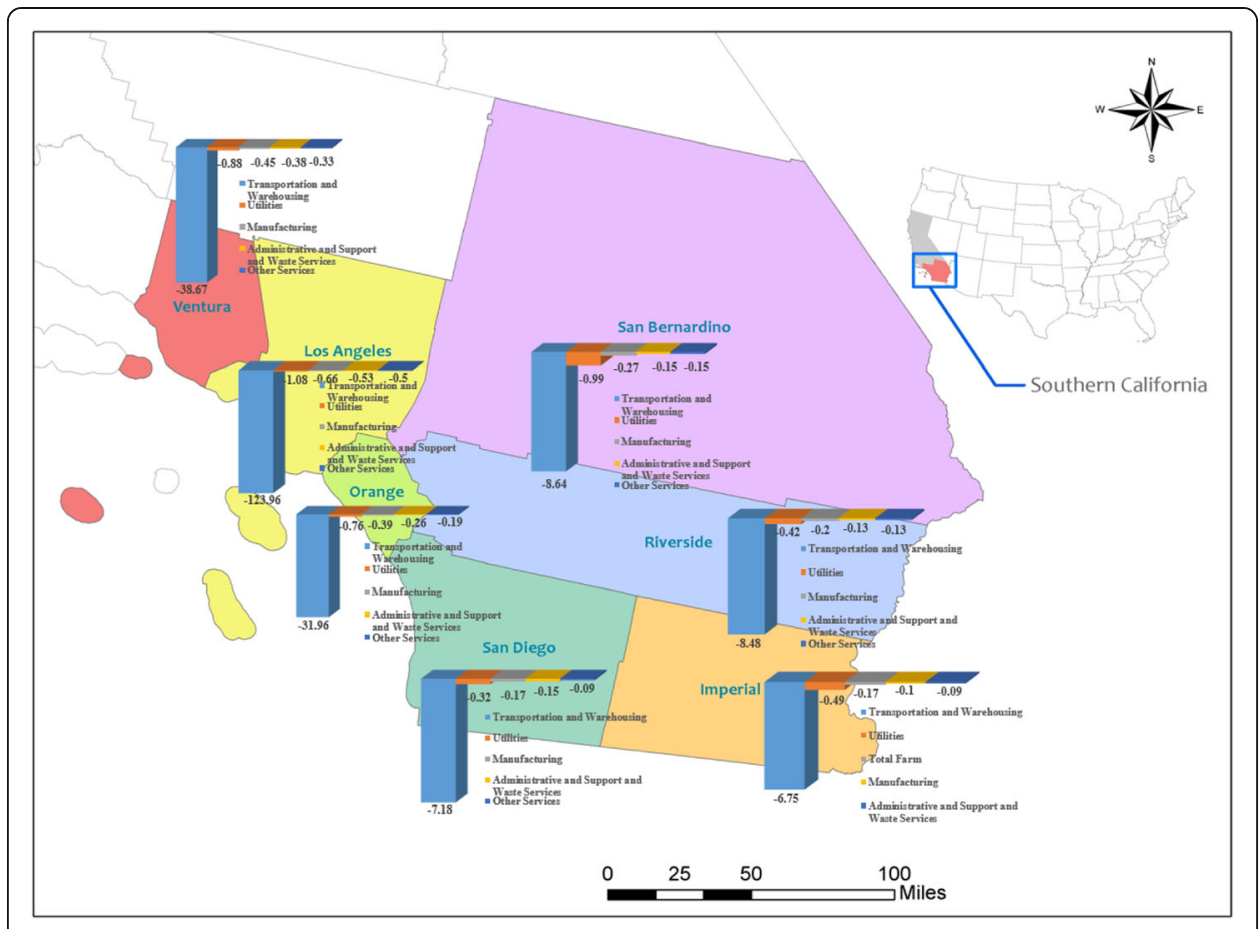

Fig. 5 The reductions of GHG emissions for major industries in seven counties

Table 6 Total effects distributed to the rest of California, the U.S. and the rest of the world

\begin{tabular}{llll}
\hline Sectors & RCA & RUS & ROW \\
\hline 1 & $-2.38(0.1)$ & $-0.00(0.0)$ & $-1.23(0.1)$ \\
2 & $-0.71(0.0)$ & $-5.40(0.5)$ & $-19.68(1.2)$ \\
3 & $-1.97(0.1)$ & $-27.06(2.6)$ & $-1.50(0.1)$ \\
4 & $-0.16(0.0)$ & $-0.00(0.0)$ & $-0.00(0.0)$ \\
5 & $-243.87(13.4)$ & $-30.16(2.9)$ & $-329.46(20.4)$ \\
6 & $-0.54(0.0)$ & $-0.00(0.0)$ & $-0.00(0.0)$ \\
7 & $-0.21(0.0)$ & $-0.00(0.0)$ & $-0.00(0.0)$ \\
8 & $-1547.38(85.3)$ & $-981.79(93.6)$ & $-1261.99(78.0)$ \\
9 & $-0.18(0.0)$ & $-0.00(0.0)$ & $-0.01(0.0)$ \\
10 & $-0.39(0.0)$ & $-0.75(0.1)$ & $-0.56(0.0)$ \\
11 & $-0.55(0.0)$ & $-0.00(0.0)$ & $-0.00(0.0)$ \\
12 & $-2.04(0.1)$ & $-0.00(0.0)$ & $-0.28(0.0)$ \\
13 & $-0.00(0.0)$ & $-0.05(0.0)$ & $-0.00(0.0)$ \\
14 & $-8.92(0.5)$ & $-0.00(0.0)$ & $-0.03(0.0)$ \\
15 & $-0.14(0.0)$ & $-0.70(0.1)$ & $-0.05(0.0)$ \\
16 & $-0.27(0.0)$ & $-1.72(0.2)$ & $-0.00(0.0)$ \\
17 & $-0.12(0.0)$ & $-0.00(0.0)$ & $-0.00(0.0)$ \\
18 & $-0.74(0.0)$ & $-0.35(0.0)$ & $-0.00(0.0)$ \\
19 & $-2.78(0.2)$ & $-1.42(0.1)$ & $-0.57(0.0)$ \\
20 & $-0.00(0.0)$ & $-0.00(0.0)$ & $-0.07(0.0)$ \\
21 & $-0.03(0.0)$ & $-0.00(0.0)$ & $-2.22(0.1)$ \\
Total & $-1813.37(0.76)$ & $-1049.41(0.44)$ & $-1617.67(0.68)$ \\
\hline 1. Unit: tons &
\end{tabular}

1. Unit: tons

2. The value in parentheses is a percentage to the total

3. A negative sign indicates the reduction of GHG emissions 


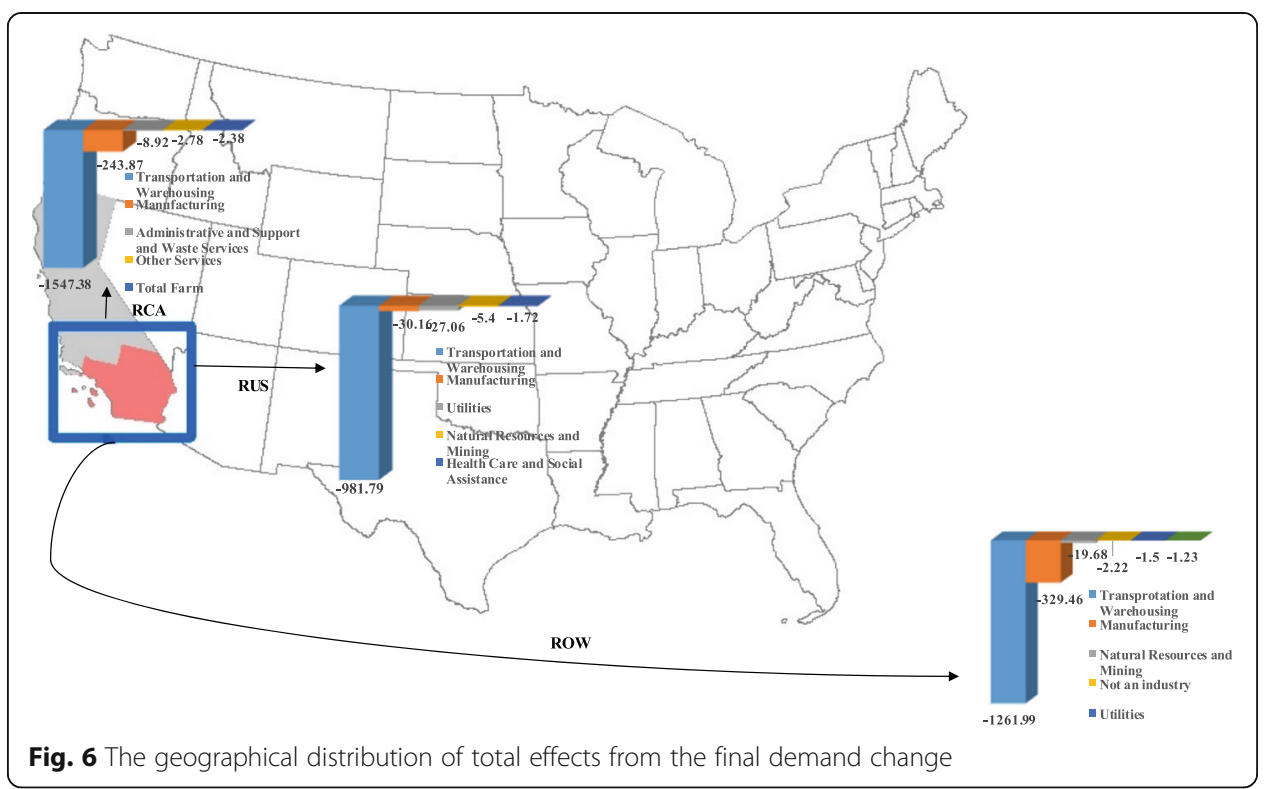

It was necessary to establish an MRIO model for measuring the inter-county spillovers of GHG emissions effect associated with economic activity changes in the Southern California region. In this research, we applied the SCI-SAM model and extended to the ESCI-SAM model for estimating the GHG emissions of the Southern California region.

Using 2008 GHG emission inventory of California and the ESCI-SAM model, we estimated GHG emissions data at the county level and measured the spillover effects by replacing of existing demand. As seen in Table 4, the estimated total GHG emissions of seven counties are 342 million tons. From the 2008 GHG emission inventory of California, $72 \%$ of GHG emissions took place in those counties. In the order of Los Angeles, San Diego and Orange, GHG emissions are high at the county level.

Based on the assumption that the final demand of the Transportation and Warehousing sector in Los Angeles County decreased 100 million dollars, we conducted spillover effect analysis. The total effects of seven counties in terms of GHG emission reductions are estimated at 238,345 tons. Among these amounts, about 53\% occurred in Los Angeles County, and Ventura and Orange followed. Applying additional procedures, we measured the effects distributed to RCA, RUS and ROW, respectively. The estimated results showed that $0.8 \%$ of total effects are passed onto RCA, $0.4 \%$ onto RUS, and $0.7 \%$ onto ROW.

Through estimating GHG emissions at a county level in this study, the local government and city planners can set up their own guidelines to meet the action plans at the state or national level. Moreover, the other stakeholders such as industry participants in a regional economy can make an appropriate decision to build the various environmental regulations especially focusing on the transportation sector. In this way, green policies implemented in California may lower GHG emissions as well as improve economic performance of the state. In order to apply the ESCI-SAM type model for the other local regions, it requires developing a similar type of SCI-SAM. Once a local environmental inter-county SAM model is constructed for any local areas including Seoul, Tokyo, Beijing, New York, etc., the same procedure of GHG emissions effect analysis described here can be applied for the local areas, measuring the spillover effects. If the environmental model of a 
local region provides an energy use account, we can expect to estimate the spillover economic impacts on the local region. Based on the model, we are also able to simulate diverse scenarios in the aspect of environmental planning involving an introduction of green economy based on the GHG emissions regulation of a local region.

\title{
Endnotes
}

${ }^{1}$ Annex I Parties are OECD countries and countries that are undergoing the process of transition to a market economy.

${ }^{2}$ Since the ratios from Equation 11 should be non-negative values, we set the negative values of PRUS which were calculated from Equation 11 to zero.

\section{Authors' contributions}

CP participated in the design of the study, the construction of model, and performed the analysis of this study. Also, CP drafted the manuscript. JP and SC conceived of the study and participated in its design and coordination. All authors read and approved the final manuscript.

\section{Competing interests}

This study is supported by the Southern California Association of Governments under contract number 10-047 (SCAG NO.10-047) through the Federal Highway Administration and Federal Transit Administration, U.S. Department of Transportation, under the Metropolitan Planning Program, Section 104(f) of Title 23, U.S. Code. Any opinions, findings, conclusions, or recommendations in this article are those of the authors and do not necessarily reflect the views of the Southern California Association of Governments and the United States Department of Transportation. Also, Climate Change Correspondence Program (2014001310006) of the Korea Ministry of Environment has partially supported the completion of this study. Publication fee of this article was supported by the World Science Culture Forum in Korea, SOItmC and the DGIST R\&D Program of the Ministry of Science, ICT and Future Planning (16-IT) of South Korea. Finally, the proportional method to estimate domestic trade flows using IMPLAN data has awarded the First IMPLAN Methods Competition Award by Minnesota IMPLAN Group, Inc. in 2012.

\section{Publisher's Note}

Springer Nature remains neutral with regard to jurisdictional claims in published maps and institutional affiliations.

\author{
Author details \\ ${ }^{1}$ International Logistics Research Department, Port \& Logistics Research Division, Korea Maritime Institute (KMI), 26, \\ Haeyang-ro 301 beon-gil Yeongdo-gu, Busan 49111, South Korea. ${ }^{2}$ Department of Urban and Regional Planning, \\ University at Buffalo, The State University of New York, 228 Hayes Hall, Buffalo, NY 14214-3087, USA. ${ }^{3}$ Department of \\ Urban Planning and Real Estate, Chung-Ang University, 84 Heukseok-ro, Heukseok-dong, Dongjak-gu, Seoul 06974, \\ South Korea. ${ }^{4}$ Department of Research and Forecasting Research and Analysis, Southern California Association of \\ Governments, 818 West 7th Street, 12th Floor, Los Angeles, CA 90017, USA.
}

Received: 4 January 2017 Accepted: 22 April 2017

Published online: 15 May 2017

\section{References}

Acs, Z. J., \& Armington, C. (2004). Employment Growth and Entrepreneurial Activity in Cities. Regional Studies, 38(November), 911-927. http://doi.org/10.1080/0034340042000280938.

AEA, (2011) Reduction and Testing of Greenhouse Gas (GHG) Emissions from Heavy Duty Vehicles - Lot 1: Strategy. Final Report to the European Commission - DG Climate Action available from https://ec.europa.eu/clima/sites/ clima/files/transport/vehicles/docs/ec_hdv_ghg_strategy_en.pdf. Accessed 20 Dec 2016.

Ahmad, N and Wyckoff, A (2003). Carbon dioxide emissions embodied in international trade of goods, OECD Directorate for Science, Technology and Industry Working Paper 2003/15. Paris: OECD Publishing. http://dx.doi.org/ $10.1787 / 421482436815$.

Audretsch, DB (2007). Entrepreneurship Capital and Economic Growth. Oxford Review of Economic Policy, 23(1), 63-78. https://ssrn.com/abstract=1151112.

CARB. (2008). Climate Change Scoping Plan: a Framework for Change, available at. http://www.arb.ca.gov/cc/ scopingplan/document/adopted_scoping_plan.pdf.

Cooke, P. (2016). The virtues of variety in regional innovation systems and entrepreneurial ecosystems. Journal of Open Innovation: Technology, Market, and Complexity, 2(1), 13. http://doi.org/10.1186/s40852-016-0036-x.

Eder, P., \& Narodoslawsky, M. (1999). What environmental pressures are a region's industries responsible for? A method of analysis with descriptive indices and input-output models. Ecological Economics, 29, 359-374.

EIA. (2009). Annual Energy Outlook 2009, DOE/EIA-0383(2009). Washington, D.C.: U.S. Energy Information Administration.

European Commission. (2014). Strategy for reducing heavy-duty vehicles' fuel consumption and CO2 emissions. COM (2014) 285 final, Brussels.

Greene, DL and Shafer, A (2003). Reducing Greenhouse Gas Emissions from U.S. Transportation. A report prepared for the Pew Center on Global Climate Change, available from http://www.c2es.org/docUploads/ustransp.pdf. Accessed 20 Dec 2016. 
Hoekstra, R., \& Janssen, M. A. (2005). Environmental Responsibility and Policy in a Two-country Dynamic Input-Output Model. Economic Systems Research, 18(1), 1-24.

Kratena, K and Meyer, I (2010). $\mathrm{CO}_{2}$ Emissions Embodied in Austrian International Trade, FIW Research Reports 2009/ 2010. Austria: Austrian Institute of Economic Research.

Lenzen, M., Pade, L.-L., \& Munksgaard, J. (2004). CO 2 Multipliers in Multi-region Input-Output Models. Economic Systems Research, 16, 391-412.

Lin, B., \& Sun, C. (2010). Evaluating carbon dioxide emissions in international trade of China. Energy Policy, 38, 613-621.

Lo, C., \& Tang, S. (2014). Institutions, Regulatory Styles, Society and Environmental Governance in China, Routledge.

McGregor, P. G., Swales, J. K., \& Turner, K. R. (2008). The $\mathrm{CO}_{2}$ 'trade balance' between Scotland and the rest of the UK: Performing a multi-region environmental input-output analysis with limited data. Ecological Economics, 66, 662-673.

Miller, RE and Blair, PD (2009). Input-Output Analysis: Foundations and Extensions. Cambridge University Press, New York.

Munksgarrd, J., \& Pedersen, K. A. (2001). $\mathrm{CO}_{2}$ accounts for open economies: producers or consumer responsibility? Energy Policy, 29, 327-334.

Nijdam, D. S., Wilting, H. C., Goedkoop, M. J., \& Madsen, J. (2005). Environmental Load from Dutch Private Consumption: How Much Damage Take Place Abroad? Journal of Industrial Ecology, 9, 147-168.

Olivier, J. G. J., Janssens-Maenhout, G., Peters, J. A. H. W., \& Wilson, J. (2011). Long-term trend in global CO2 emissions 2011 report. The Hague: PBL Netherlands.

Park, J. Y. (2006). Estimation of State-by-State Trade Flows for Service Industries, presented at North American Meetings of the Regional Science Association International 53rd Annual Conference. Toronto, Canada: Fairmont Royal York Hotel.

Park, JY and Page WG (2017). Innovative Green Economy, Urban Economic Performance and Urban Environments: an Empirical Analysis of U.S. Cities. European Planning Studies (under second review)

Park, C and Park JY (2016). Panama Canal expansion, US trade diversion from west coast seaports and urban innovation. Journal of Open Innovation: Technology, Market, and Complexity, 2016 (2): 12. doi:10.1186/s40852-016-0040-1

Park, J. Y., Gordon, P., Moore, J. E., II, \& Richardson, H. W. (2009). A two-step approach to estimating state-to-state commodity trade flows. The Annals of Regional Science, 43, 1033-1072.

Park, JY, Son, M and Park, C (2017). Natural Disasters and Deterrence of Economic Innovation: A Case of Temporary Job Losses by Hurricane Sandy. Journal of Open Innovation: Technology, Market, and Complexity, 3:5. doi:10.1186/s40852017-0055-2.

Peters, G. P. (2008). From production-based to consumption-based national emission inventories. Ecological Economics, $65,13-23$

Peters, G. P., \& Hertwich, E. G. (2006a). Pollution embodied in trade: The Norwegian case. Global Environmental Change, $16,379-387$.

Peters, G. P., \& Hertwich, E. G. (2006b). The Importance of Imports for Household Environmental Impacts. Journal of Industrial Ecology, 10(3), 89-109.

Sánchez-Chóliz, J., \& Duarte, R. (2005). $\mathrm{CO}_{2}$ emissions embodied in international trade: evidence for Spain. Energy Policy, 32, 1999-2005.

Turner, K., Lenzen, M., Wiedmann, T., \& Barrett, J. (2007). Examining the global environmental impact of regional consumption activities - Part 1: A technical note on combining input-output and ecological footprint analysis. Ecological Economics, 62, 37-44.

U.S. DOS. (2007). U.S. Climate Action Report 2006, Office of Global Change. Washington, DC: U.S. Department of State.

UNFCCC, 1997, Kyoto Protocol to the United Nations Framework Convention on Climate Change (UNFCCC), FCCC/CP/ 1997/L.7/Add.1. Bonn: United Nations Framwork Convention on Climate Change.

Wiedmann, T., Lenzen, M., Turner, K., \& Barrett, J. (2007). Examining the global environmental impact of regional consumption activities - Part2: Review of input-output models for the assessment of environmental impacts embodied in trade. Ecological Economics, 61, 15-26.

Wyckoff, A. W., \& Roop, J. M. (1994). The embodiment of carbon in imports of manufactured products: Implications for international agreements on greenhouse gas emissions. Energy Policy, 22, 187-194.

\section{Submit your manuscript to a SpringerOpen ${ }^{\circ}$ journal and benefit from:}

- Convenient online submission

- Rigorous peer review

- Immediate publication on acceptance

- Open access: articles freely available online

- High visibility within the field

- Retaining the copyright to your article

Submit your next manuscript at $\gg$ springeropen.com 